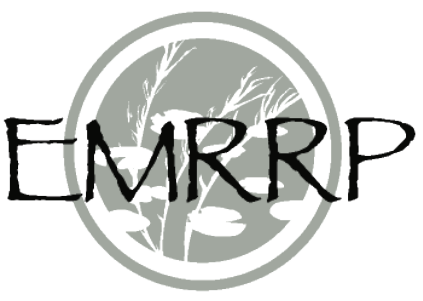

\title{
Remotely Sensed Habitat Assessment of Bottomland Hardwood and Swamp Habitat: West Shore Lake Pontchartrain Hurricane Storm Damage Risk Reduction System Potential Impact Area
}

by Christina L. Saltus and Glenn M. Suir

PURPOSE: This study used remote sensing techniques to identify and assess the current condition of bottomland hardwood (BLH) and swamp habitats within the West Shore Lake Pontchartrain (WSLP) hurricane storm-damage risk reduction system (HSDRRS) project area. This effort provides baseline knowledge of the location and quality of these habitats prior to the construction of the WSLP HSDRRS project. The resultant products will assist the USACE-New Orleans District (MVN) by informing ecosystem decision-making related to environmental assessments.

INTRODUCTION: In 2016 the MVN was authorized to construct a hurricane storm-damage risk reduction levee to protect the communities in the vicinity of St. Charles, St. James, and St. John the Baptist Parishes, Louisiana, in accordance with the Water Infrastructure Improvement for the Nation Act (WIIN Act, Public Law 114-322). ${ }^{1}$ This area is part of the Upper Pontchartrain hydrologic basin known for its extensive forested wetland habitat. Previous studies and reports have evaluated forested wetland processes, productivity, and degradation near the WSLP project area (Effler et al. 2007; Shaffer et al. 2009 and 2016; Krauss et al. 2017). In 1998, the Upper Pontchartrain basin consisted of 44,515 ha of BLH and 77,550 ha of swamp (Louisiana Coastal Wetlands Conservation and Restoration Task Force and the Wetlands Conservation and Restoration Authority 1998). Recent mapping of the Upper Pontchartrain basin has been limited, consisting of generalized woody wetland characterizations derived from Landsat satellite imagery, a moderate spatial-resolution imagery at $30 \mathrm{~m}$ resolution, without distinction between BLH and swamp habitats (Yang et al. 2018). Therefore, the WSLP project area needed updated assessments of the location, extent, and quality of BLH and swamp habitats to evaluate environmental impacts prior to construction. This investigation sought to use WorldView-3 (Maxar 2020) high spatial-resolution satellite imagery to identify BLH and swamp in the WSLP area of interest and to quantify the vegetative biomass of each habitat type to characterize vegetation health. The resultant products will support the environmental impacts and mitigation decision-making process.

Remote sensing data and techniques provide tools for assessing expansive areas where groundbased survey methods may be cost- and time-prohibitive or where site access is limited (Adam, Mutanga, and Rugege 2010; Klemas 2013; McCarthy, Merton, and Muller-Karger 2015). Remotely sensed data also benefit landscape analyses because they can be used to develop metrics for detecting and quantifying coastal ecosystem structure and function at a multitude of spatial, spectral, and temporal scales. In particular, the use of high-resolution satellite multispectral imagery ( 1 to $3 \mathrm{~m}$ ), such as those collected from the WorldView satellite series, provide the advantage of increased spatial and spectral capabilities that are crucial for differentiating habitat in a coastal wetland ecosystem (Rapinel et al. 2014; Lane et al. 2015; McCarthy, Merton, and Muller-Karger

1. Water Infrastructure Improvements for the Nation Act of 2016, Pub. L. No. 114-322, 130 Stat. 1628 (2016). 
2015). This study advances methods developed during a recently funded Ecosystem Management and Restoration Research Program (EMRRP) research work units, Use of Remote Sensing Technologies and Field Data Collection to Quantify the Effects of Dedicated Dredging and Use of Dredged Sediments for Ecosystem Restoration (Suir, Sasser, and Harris 2020). These studies used moderate spatial and spectral resolution imagery, ground-based survey data, and a combination of image classification techniques (that is, spectral indices, supervised and unsupervised classifications) to differentiate land and water areas in nonforested wetland habitats. These studies also used the Normalized Difference Vegetation Index (NDVI), which has well-established correlations to photosynthetic activity, aboveground biomass, and leaf area index. Therefore, the NDVI serves as a primary measure of vegetation condition, function, recovery, sustainability, and useful estimates of primary productivity, and wetland species distributions as well as resistance to, and recovery from, anthropogenic activities and episodic events (Carle 2013; Suir and Sasser 2017; Suir, Saltus, Reif 2018; Suir and Sasser 2019a, b). This investigation broadens the application of wetland classifications and NDVI analysis methods presented in previous EMRRP-funded research (Suir and Sasser 2019b) to assess baseline conditions in a forested wetland habitat using highresolution satellite imagery and NDVI as a measure of vegetation productivity and vigor.

\section{METHODS}

Study Area and Field Data. The WSLP study area is located in south Louisiana in St. John the Baptist and St. Charles parishes (figure 1). Bounded by Lake Maurepas to the north and the Mississippi River to the south, the project area encompasses 23,764 ha and is partially contained within the Maurepas Swamp Wildlife Management Area. Geologic development of this area occurred during the forming and shifting of historical Mississippi River delta lobes (that is, Cocodrie and St. Bernard lobes) (Effler et al. 2007). Subsequently, this area became a robust wetland system complex with the second-largest contiguous coastal forest in Louisiana (Effler et al. 2007). In October 2019, MVN personnel performed ground-based surveys to identify BLH and swamp habitat in the project area. The surveys consisted of 15 sample sites: 6 sites represented BLH habitat and 9 sites denoted swamp habitat (figure 1). For each sample site, MVN personnel recorded the habitat type, the overstory species dominance (that is, BLH [pumpkin ash, roughleaf dogwood, water hickory and water oak] and swamp [that is, Drummond red maple, cypress, pumpkin ash, willow and tupelo]) and visual assessments of habitat health (that is, healthy, low stress, medium stress, and very stressed). In addition, four coastwide reference monitoring stations (CRMS) swamp habitat sites (that is, cypress, tupelo, and red maple) identified in the project area were used in this investigation. 


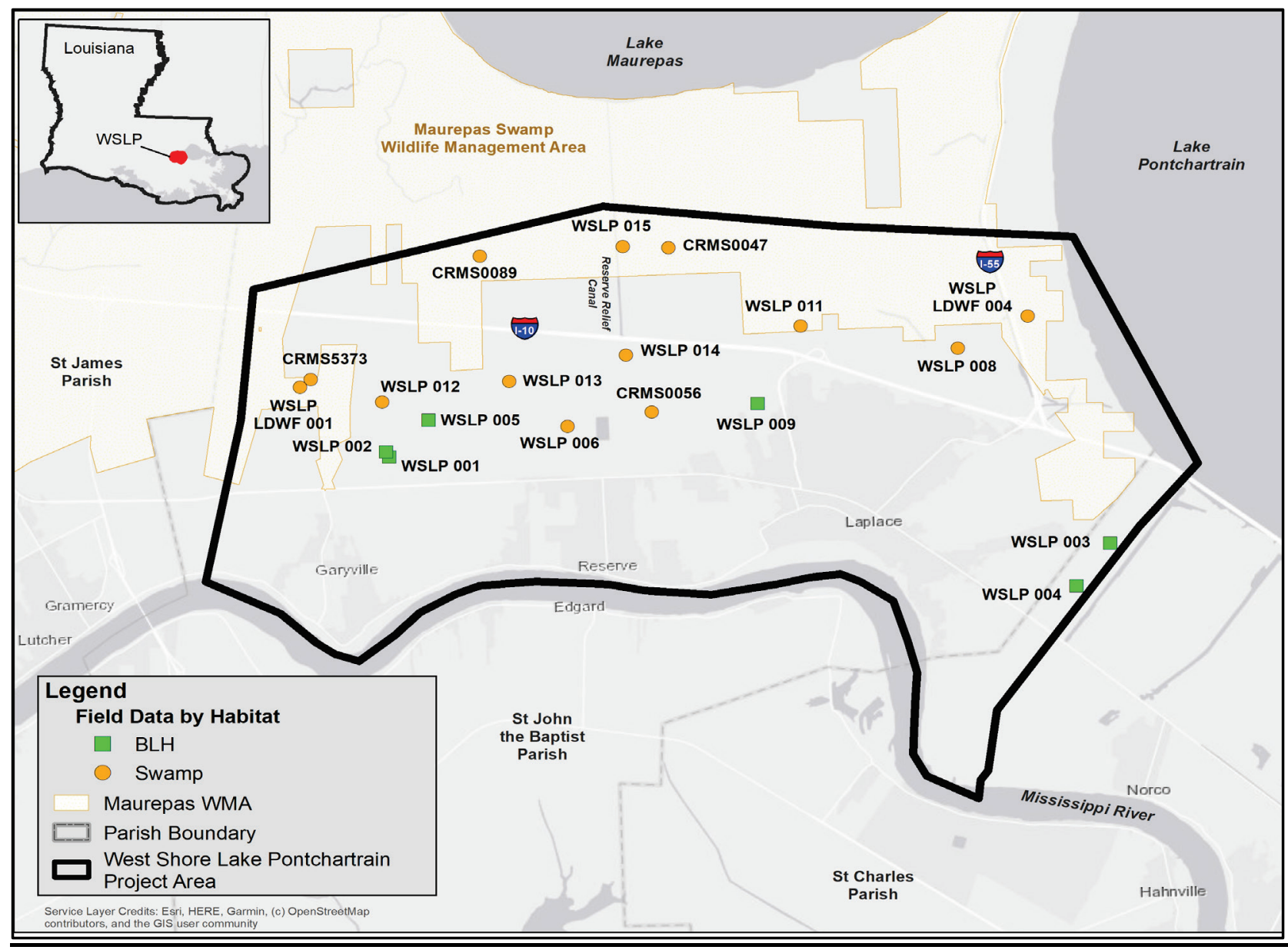

Figure 1. West Shore Lake Pontchartrain study area and ground-based survey points.

\section{Remote Sensing}

Image Acquisition and Processing. Cloud-free, leaf-on WorldView-3 (WV3) high-resolution satellite imagery collected on 2 April 2019 and 20 April 2019 were used to detect and assess vegetation health of BLH and swamp habitat in the WSLP study area. Seven scenes of multispectral imagery (each consisting of eight multispectral bands: coastal [397-454 nm], blue [445-517 nm], green [507-586 nm], yellow [580-629 nm], red [626-696 nm], red edge [698-749 nm], nearinfrared 1 [765-899 nm], and near-infrared 2 [857-1039 nm]) acquired through the Maxar EnhancedView Web Hosting Service were required for full coverage and had a spatial resolution of $1.24 \mathrm{~m}$. Remote sensing software, ENVI version 5.5 (L3Harris Geospatial Solutions, Boulder, Colorado), was used to radiometrically and atmospherically correct all satellite scenes. This process consists of transforming electromagnetic radiance captured from the satellite sensor (represented as digital numbers) to spectral radiance values and then transforming radiance into reflectance by applying corrections for solar illumination geometry (Strahler et al. 1999; Chander, Markham, and Helder 2009; Tarantino et al. 2012). Prior to habitat classification and vegetative health assessments, all scenes were mosaicked and color balanced to enable classification methods. All analyses documented in this report were conducted in ENVI version 5.5 software unless otherwise noted. 
May 2021

Classification Methods. This study identified BLH and swamp habitats in the WSLP study area using a pixel-based classification approach. This approach used training data (according to MVN and CRMS ground-based surveys) in conjunction with the supervised maximum likelihood classification (MLC) workflow. MLC is a commonly used parametric image classification technique that compares the spectral band probability distributions of each training class to an image pixel value then assigns the pixel to the most relevant class (Echeverria et al 2006; Baptista and Haertel 2010; Lu et al. 2012). To assist in habitat mapping, the following ancillary data were used: St. John the Baptist Parish aerial photography (3 in spatial resolution, 2018), National Agriculture Imagery Program aerial photography (11 September 2017), WV3 imagery (02 October 2015), National Land Cover Database (2016), and National Wetlands Inventory (1988). The six classes chosen for identification in the study area included swamp, BLH, other vegetation (that is, grassland and upland vegetation), developed areas, agricultural fields, and water (consisting of open water, aquatic vegetation, and mudflats).

The habitat classification was conducted in two phases by partitioning the image into forested and nonforested areas according to the Wide Range Dynamic Vegetation Index (WRDVI). This spectral index used the WV3 red and near infrared (NIR) spectral bands along with a weighted coefficient to increase the spectral sensitivity of more densely vegetated areas and therefore enhance the detection of forested versus nonforested areas (equation 1) (Gitelson 2004; Henebry, Viña, and Gitelson 2004). The WRDVI is calculated using the following equation:

$$
W R D V I=\frac{(a * N I R-R e d)}{(a * N I R+R e d)}
$$

where $a$ is the weighting coefficient (ENVI Default $=0.2$ ), NIR is the WV3 NIR spectral band value, and Red is the WV3 red spectral band value (Henebry, Viña, and Gitelson 2004). The resultant value range of the WRDVI is -1 to 1 . Through visual interpretation of the imagery using the value ranges, value thresholds were selected to create masks representing the nonforested and forested areas. The nonforested area was represented by WRDVI values ranging between -1 to -0.3 , while the forested area was partitioned using WRDVI values ranging between -0.3 to 1 .

The first phase of the classification process included the detection of forested areas. The nonforested area mask was applied to the mosaicked image to exclude all nonforested areas such as open water, agricultural fields, and developed areas prior to classification, so that only forested areas were available for analysis. Then, regions of interest (ROIs) were generated from the MVN and CRMS ground-survey data to detect BLH and swamp habitat, a total of 17 and 13 ROIs respectively. Additional ROIs were needed to distinguish other vegetation such as shrubs (7 ROIs) and aquatic vegetation (15 ROIs), which were not captured by the nonforested mask due to their elevated spectral signature values. The forested area classification included the following classes: BLH, swamp, other vegetation, and aquatic vegetation. Prior to classification, a pair-wise ROI separability algorithm was run on all training samples to ensure that the spectral signatures of each ROI was discernible to reduce classification confusion between classes.

The second phase of habitat differentiation included the classification of nonforested areas. The forested area mask excluded all forested areas such as BLH and swamp prior to classification so that only nonforested areas were available for identification. Then, ROIs were generated according to visual interpretation (using the 2019 imagery and ancillary data) for the following nonforested area classification classes: agriculture (5 ROIs); developed (60 ROIs); water (5 ROIs); and aquatic 
vegetation (5 ROIs). As with the forested classes, a pair-wise ROI separability algorithm ensured that the spectral signatures of each ROI class were distinct to minimize classification errors. Finally, the resultant phase one and two classifications were merged to produce the final classified image in NAD83 Louisiana State Plane South coordinate system with a spatial resolution of $1.45 \mathrm{~m}$. Habitat class statistics were generated using the ArcGIS 10.7 (ESRI 2015) Tabulate Area zonal statistics tool for the WSLP study area boundary and reported in ac and percent of total area.

Habitat Health Assessment. NDVI values were generated from the WV3 imagery. It is a ratio of spectral bands to measure an ecosystem's ability to capture solar energy and convert it to organic carbon or biomass (equation 2) (An, Price, and Blair 2013). The NDVI data were created using a variant of the standard equation (Rouse et al. 1974):

$$
N D V I=\frac{N I R-R e d}{N I R+R e d}
$$

where NIR is the WV3 near infrared spectral band value, and Red is the WV3 Red spectral band value. The NDVI values can range from -1 to 1 , where values between -1 to zero (0) typically represent nonvegetation features (for example, water, cloud, and impervious surfaces), and values between zero (0) to 1 typically represent green vegetation (Datt 1999; Sims and Gamon 2002). Generally, the higher the NDVI value, the higher the biomass, productivity, and vigor of the tree or plant. For each class (that is, agriculture, BLH, developed, other vegetation, swamp, and water) of the resultant habitat classification, the mean NDVI values were calculated using the Zonal statistics tool in ESRI ArcGIS 10.7 software. The final NDVI image was projected to NAD83 Louisiana State Plane South coordinate system with spatial resolution of $1.45 \mathrm{~m}$.

\section{RESULTS AND DISCUSSION}

Habitat Classification. The WSLP study area encompasses 23,764 ha, comprised primarily of forested wetland habitat, water, and developed areas. The six habitat classes identified within the study area included swamp, developed areas, BLH, water, other vegetation, and agriculture (figure 2 , table 1). The water class consists of open water, aquatic vegetation, and mudflats, while the other vegetation class includes grasslands, pasture, marsh, right-of-way areas, and shrubs. The developed class includes commercial, residential, and industrial areas such as roadways, residences, anthropogenic lakes, airports, and oil refineries.

The classification results indicated that swamp habitat is more common north of the I-10 corridor, whereas the majority of BLH habitat is found closer to the developed areas south of the I- 10 corridor and along canals such as the Reserve Relief Canal (figure 2), possibly due to higher elevations. Developed areas occurred primarily along the Mississippi River below US Route 61 and in close proximity to the I-10 and I-55 interchange. Water areas were notable on either side of the Reserve Relief Canal. The presence of these water features may be due in part to water level fluctuations due to the canal's connection to Lake Maurepas to the north. From visual assessments of the final classification result, some class confusion may have occurred between agriculture and other vegetation classes such as pasture and grasslands because of the similarities in their spectral signatures. 
ERDC/TN EMRRP-SI-39

May 2021

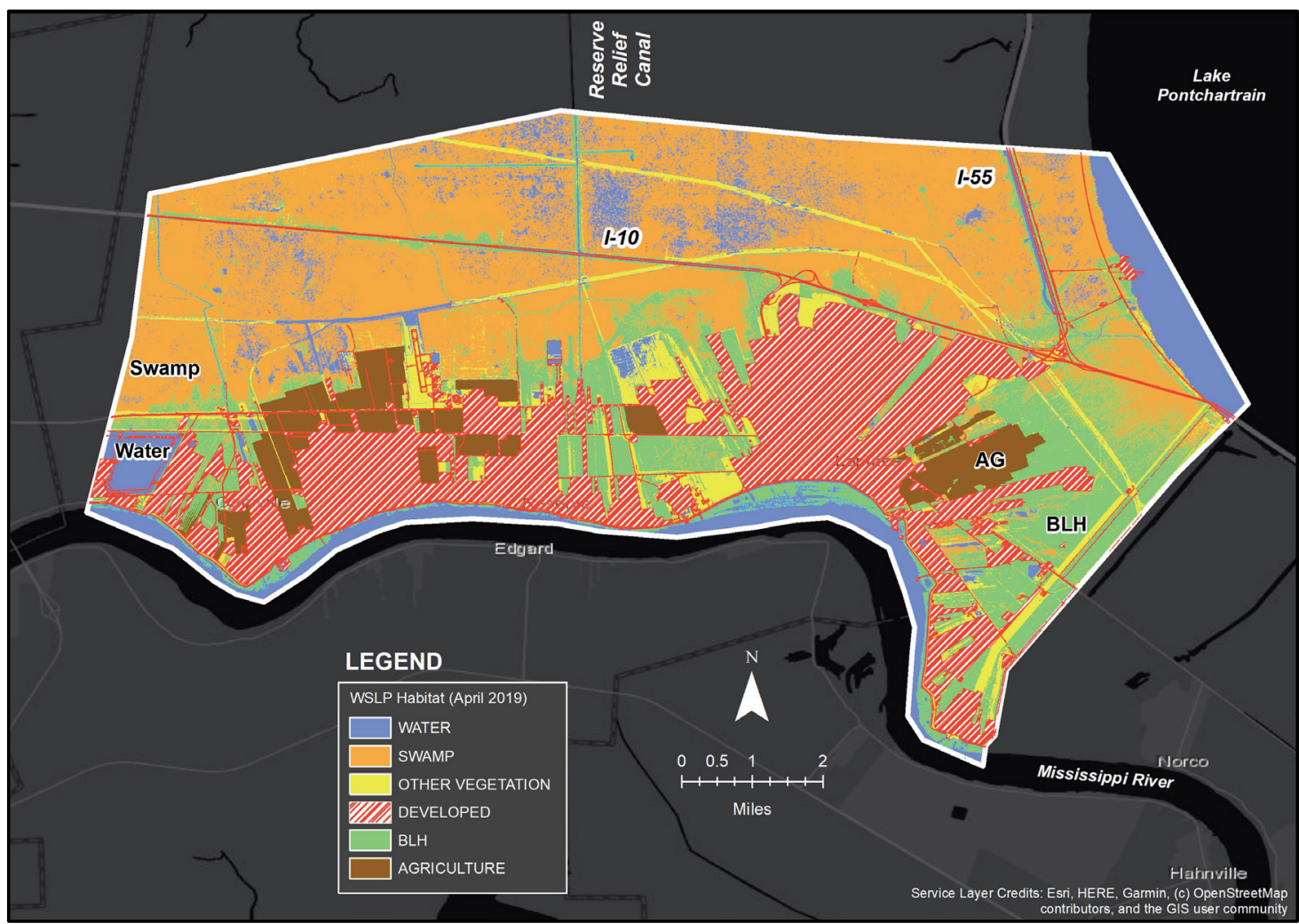

Figure 2. West Shore Lake Pontchartrain project habitat classification data using April 2019 Worldview-3 Imagery. The following habitats and hectares for each are as follows: water (in blue) comprises 2,964 ha, swamp (in orange) comprises 9,262 ha, other vegetation (in light green) comprises 1,686 ha, developed (in red and white stripes) comprises 4,898 ha, bottomland hardwood (in green) comprises 3,716 ha, and agriculture (in brown) comprises 1,238 ha.

Table 1 shows each class, total class acreage, and total class percentage area within the WSLP study area. Swamp habitat represented the highest coverage, with $39.0 \%$ of the total land area in the WSLP study area and a total of 9,262 ha. The next largest class was the developed areas, including the cities of Garyville, Reserve, and Laplace, with $20.6 \%$ of the total WSLP study area (4,898 ha). BLH habitat was third highest, with $15.6 \%$ of the total land area $(3,716 \mathrm{ha})$, followed by water with $12.5 \%$ (2,964 ha), other vegetation with $7.1 \%$ (1,686 ha), and agriculture with $5.2 \%(1,238 \mathrm{ha})$.

Because of the limited ground survey data available, all samples were required for ROI development to ensure the best possible habitat classification result. Therefore, the study team could not conduct an accuracy assessment. However, a qualitative assessment by the project delivery team, providing local expert knowledge, indicated that the classification result met expectations. 


\begin{tabular}{lrr}
\hline $\begin{array}{l}\text { Table 1. WSLP habitat classification statistics, including the total acreage per } \\
\text { class and the percentage of total WSLP study area per class. }\end{array}$ \\
\hline Habitat class & Hectares & $\begin{array}{r}\text { \% of Total } \\
\text { area }\end{array}$ \\
\hline Swamp & 9,262 & $39.0 \%$ \\
\hline Developed & 4,898 & $20.6 \%$ \\
\hline BLH & 3,716 & $15.6 \%$ \\
\hline Water & 2,964 & $12.5 \%$ \\
\hline Other vegetation & 1,686 & $7.1 \%$ \\
\hline Agriculture & 1,238 & $5.2 \%$ \\
\hline \hline Total & 23,764 & $100 \%$ \\
\hline
\end{tabular}

NDVI Assessments. Figure 3 illustrates the spatial variability and patterns of WV-derived NDVI within the WSLP project area. The project area had minimum, maximum, and mean NDVI values of $-0.99,0.99$, and 0.54 , respectively. The range of NDVI values are depicted in figure 3 , with vegetated features represented by high NDVI values (light and dark greens), and nonvegetated features represented by low NDVI values (reds and oranges). The forested areas (that is, BLH and swamp) primarily consisted of high productivity (dark greens) east of the Reserve Relief Canal and moderate to high productivity (yellow and light greens) west of the Reserve Relief Canal (figure 3).

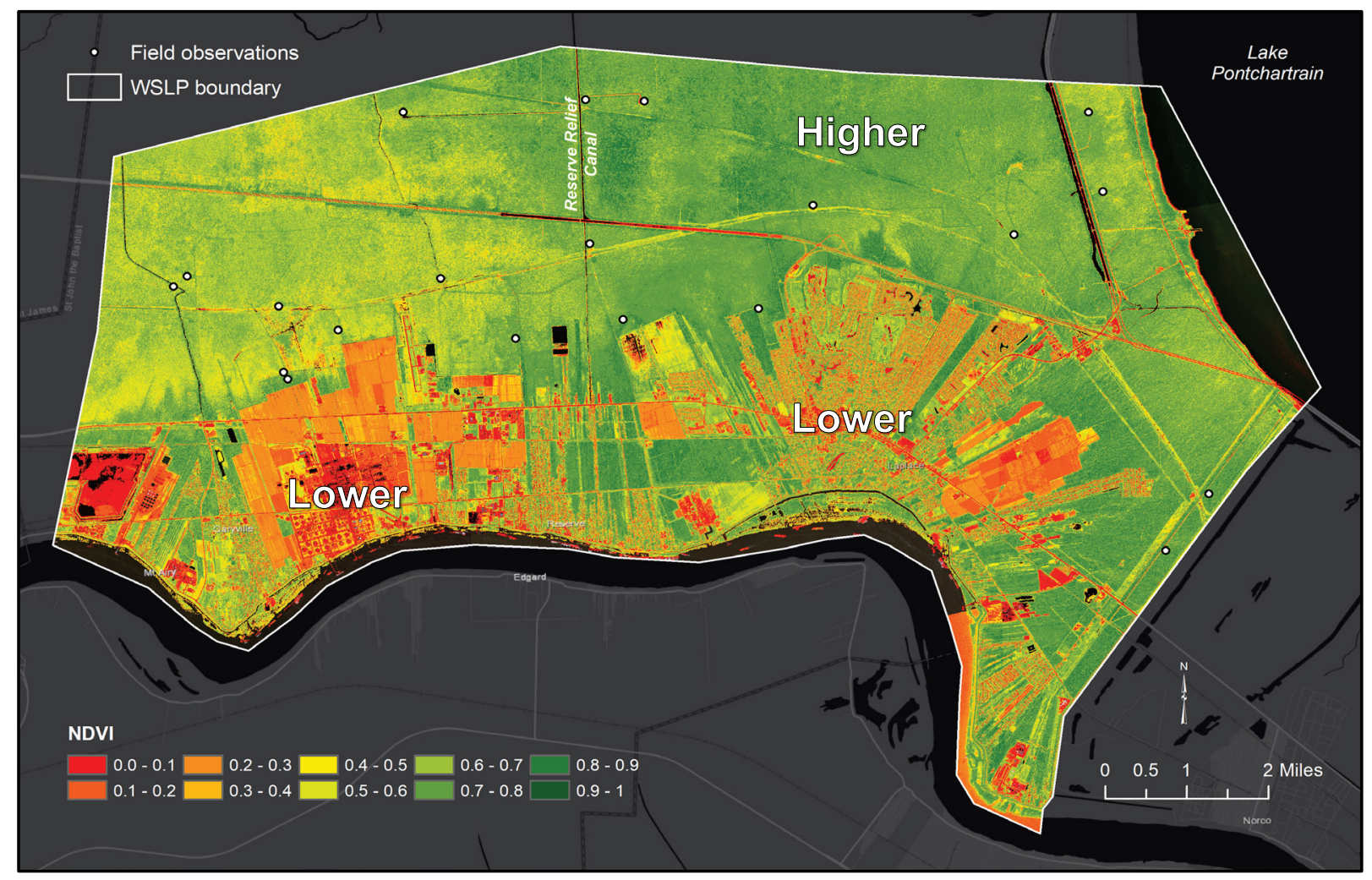

Figure 3. Productivity classification based on quartile distribution of WorldView-3-derived normalized difference vegetation index (NDVI) values from April 2019 in the WSLP project area. The NDVI values in the project area range from zero to one, where values between zero to 0.30 (red and orange) represented mostly nonvegetation features (for example, water, developed areas, and barren fields), and values between 0.30 to 1 (yellow and green) mostly represented green vegetation such as BLH and swamp. 
Figure 4 shows the mean NDVI values from April 2019 for each class (that is, agriculture, BLH, developed, other vegetation, swamp, and water) in the WSLP project area. The mean NDVI values ranged from a low of $0.14 \pm 0.47$ to a high of $0.75 \pm 0.09$ for the water and BLH classes, respectively. Mean NDVI value $(0.28 \pm 0.36)$ of the two nonvegetated classes (developed and water) were all significantly lower than the combined mean NDVI value $(0.69 \pm 0.1)$ of the three primary vegetation classes (BLH, other vegetation, and swamp). The agriculture areas were largely void of vegetation (April is typically the start of the agricultural growing season in south Louisiana) and therefore consisted of a low mean NDVI value $(0.26 \pm 0.11)$. The mean NDVI values for each of the three primary vegetation classes were $0.64 \pm 0.12,0.67 \pm 0.09$, and $0.75 \pm 0.09$ for the other vegetation, swamp, and BLH classes, respectively.

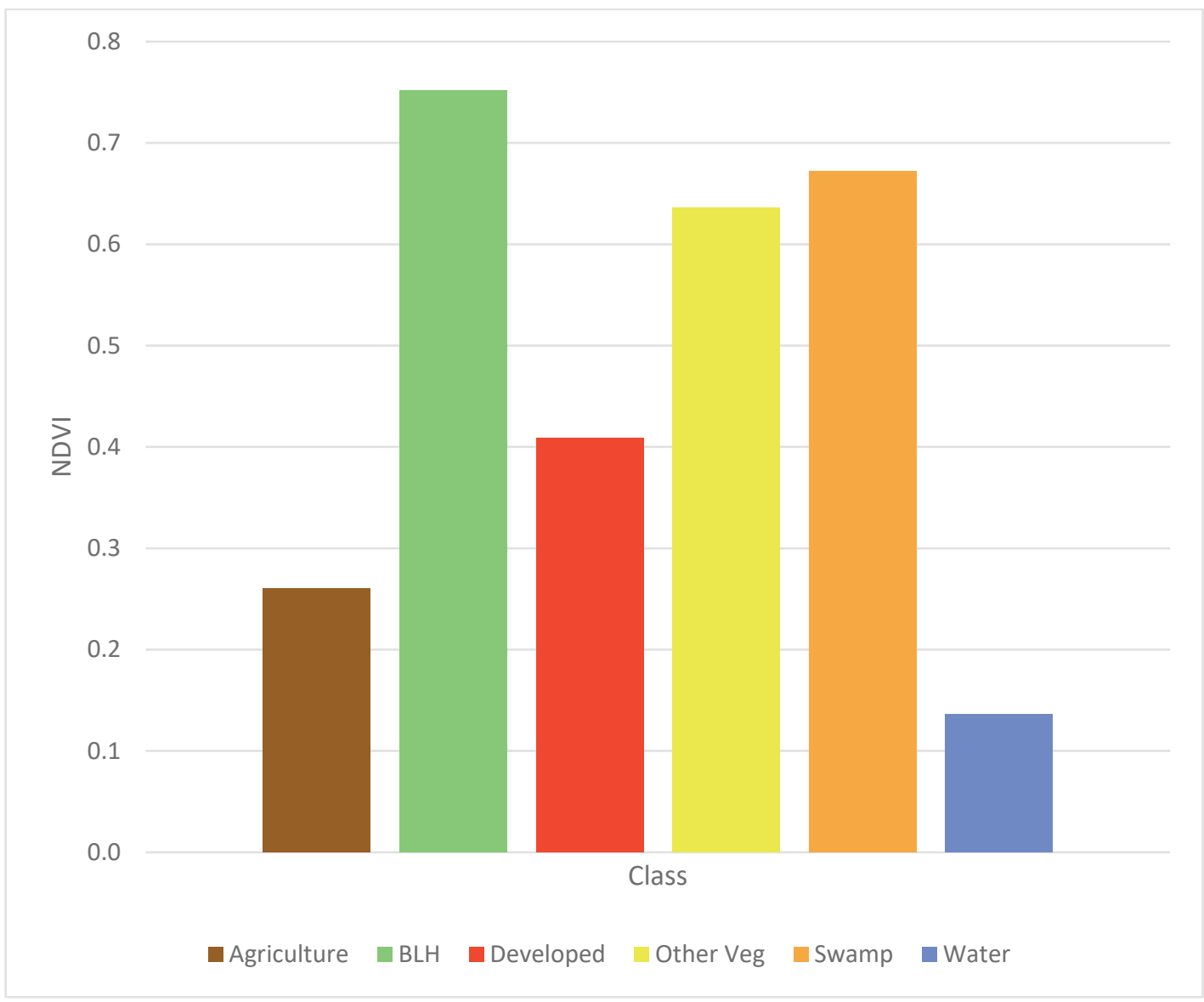

Figure 4. Mean NDVI values for each class within the WSLP study area.

CONCLUSIONS: This investigation sought to use MLC and NDVI analysis techniques to describe the location and quality of BLH and swamp habitat in the WSLP HSDRRS project area using WV3 satellite imagery collected in April 2019. The conducted MLC analysis identified the location and extent of BLH and swamp habitats in the project area, with swamp being most prevalent. Swamp habitat was located mostly in interior regions interspersed with water, while BLH habitat was primarily confined to areas between swamp habitat and developed areas. This study assessed biomass and habitat quality using NDVI estimations from WV3 imagery and evaluated according to habitat type. The analysis revealed that BLH habitat represented the highest mean NDVI values, followed closely by swamp and other vegetation habitats. Additionally, results illustrated differences in swamp habitat NDVI values on either side of the Reserve Relief Canal. 
Including additional field sites as training data, particularly within the habitat transition zone between BLH and swamp, will improve future BLH and swamp habitat detection. The remote sensing analysis for this study focused on a single time record in April 2019. While these analyses benefit and inform environmental assessments, multiseasonal and temporal NDVI assessments provide further benefit by monitoring trends in habitat health throughout the project's lifecycle.

ACKNOWLEDGEMENTS: This research was funded by and prepared for the U.S. Army Corps of Engineers, New Orleans District. The authors would like to thank Patrick Smith (MVN) and Catherine Breaux, United States Fish and Wildlife Service (USFWS) for providing their expertise and field data for this project.

POINTS OF CONTACT: This technical note was written by Christina L Saltus and Glenn M. Suir, Environmental Laboratory (EL), U.S. Army Engineer Research and Development Center (ERDC). For additional information, contact Christina Saltus (225) 200-8539, Christina.L.Saltus@, usace.army.mil.

This technical note should be cited as follows:

Saltus, Christina L., and Suir, Glenn M. 2021. Remotely Sensed Habitat Assessment of Swamp and Bottomland Hardwood Habitat: West Shore Lake Pontchartrain Hurricane Damage Risk Reduction System Potential Impact Area. ERDC/TN EMRRP-SI-39. Vicksburg, MS: US Army Engineer Research and Development Center.

\section{REFERENCES}

Ana, Nan, Kevin P. Price, and John M. Blair. 2013. "Estimating Above-Ground Net Primary Productivity of the Tallgrass Prairie Ecosystem of the Central Great Plains using AVHRR NDVI." International Journal of Remote Sensing 34(11): 3717-3735.

Batista, Marlos Henrique, and Victor Haertel. 2010. "On the classification of remote sensing high spatial resolution image data." International Journal of Remote Sensing (31):20, 5533-5548. https://doi.org/10.1080/01431160903485786.

Carle, Melissa M. 2013. Spatial Structure and Dynamics of the Plant Communities in a Prograding River Delta: Wax Lake Delta, Atchafalaya Bay, Louisiana. PhD Dissertation. Louisiana State University.

Chander, Gyanesh., Brian L. Markham, and Dennis L. Helder. 2009. "Summary of Current Radiometric Calibration Coefficients for Landsat MSS, TM, ETM+, and EO-1 ALI Sensors." Remote Sensing of Environment 113(5): 893-903.

Datt, Bisun. 1999. “A New Reflectance Index for Remote Sensing of Chlorophyll Content in Higher Plants: Tests Using Eucalyptus Leaves.” Journal of Plant Physiology 154 (1): 30-36.

Echeverria, Cristian, David Coomes, Javier Salas, Jose Marıa Rey-Benayas, Antonio Lara, and Adrian Newton. 2006. "Rapid Deforestation and Fragmentation of Chilean Temperate Forests." Biological Conservation 130(4): 481494.

Effler Rebecca S., Gary P. Shaffer, Susanne S. Hoeppner, and Richard S. Goyer. 2007. Ecology of the Maurepas Swamp: Effects of salinity, nutrients, and insect defoliation. In: Ecology of Tidal Freshwater Forested Wetlands of the Southeastern United States. Springer, Dordrecht, 349-384. 


\section{ERDC/TN EMRRP-SI-39}

\section{May 2021}

Elhadi, Adam, E., Onisimo Mutanga, and Denis Rugege. 2010. "Multispectral and Hyperspectral Remote Sensing for Identification and Mapping of Wetland Vegetation: A Review." Wetlands Ecology Management (18): 28-296. https://doi.org/10.1007/s11273-009-9169-z.

Environmental Systems Research Institute (ESRI). 2015. ArcGIS Desktop: Release 10. Redlands, CA: Environmental Systems Research Institute.

Gitelson, Anatoly. 2004. "Wide Dynamic Range Vegetation Index for Remote Quantification of Biophysical Characteristics of Vegetation." Journal of Plant Physiology 161, No. 2: 165-173.

Henebry, Geoffrey M., Andrés Viña, and Anatoly Gitelson. 2004. "The Wide Dynamic Range Vegetation Index and its Potential Utility for Gap Analysis.” Gap Analysis Bulletin 12: 50-56.

Krauss, Ken W., Gary P. Shaffer, Richard F. Keim, Jim L. Chambers, William B. Wood, and Stephen B. Hartley. 2017. "Performance Measures for a Mississippi River Reintroduction into the Forested Wetlands of Maurepas Swamp." US Geological Survey Scientific Investigations Report 2017-5036. https://doi.org/10.3133/sir20175036.

Lane, Charles R., Oleg Anenkhonov, Hongxing Liu, Bradley C. Autrey, and Victor Chepinoga. 2015. "Classification and Inventory of Freshwater Wetlands and Aquatic Habitats in the Selenga River Delta of Lake Baikal Russia, Using High-Resolution Satellite Imagery." Wetlands Ecology and Management 23: 195. https://doi.org/10.1007/s11273-014-9369-z.

Louisiana Coastal Wetlands Conservation and Restoration Task Force and the Wetlands Conservation and Restoration Authority. 1998. "Coast 2050: Toward a sustainable Coastal Louisiana." Baton Rouge, LA: Louisiana Department of Natural Resources.

Lua, Dengsheng, Guiying Lia, Emilio Morana, Corina C. Freitasb, Luciano Dutrab, and Sidnei J.S. Sant'Anna. 2012. "A Comparison of Maximum Likelihood Classifier and Object-Based Method Based on Multiple Sensor Datasets for Land-Use/Cover Classification in the Brazilian Amazon." Proceedings of the $4^{\text {th }}$ GEOBIA May $7-$ 9 2012, Rio de Janeiro, Brazil.

Maxar. 2020. Maxar Constellation. Westminster, CO: Maxar. https://www.maxar.com/constellation.

McCarthy, Matthew J., Elizabeth J. Merton, and Frank E. Muller-Karger. 2015. "Improved Coastal Wetland Mapping using Very-high 2-Meter Spatial Resolution Imagery." International Journal of Applied Earth Observation and Geoinformation (40): 11-18.

Rapinel, Sebastien, Bernard Clement, Sylvie Magnanon, Vanessa Sellin, Laurence Hubert-Moy. 2014. "Identification and Mapping of Natural Vegetation on a Coastal Site using a Worldview-2 Satellite Image." Journal of Environmental Management 144 (1): 236-246.

Rouse, J. W. Jr, R. H. Haas, J. A. Schell and D. W. Deering. 1974. "Monitoring Vegetation Systems in the Great Plains with ERTS." Paper presented at the Proceedings, Third Earth Resources Technology Satellite-1 Symposium. Washington, DC: Goddard Space Flight Center.

Shaffer, Gary P., John W. Day, Demetra Kandalepas, William B. Wood, Rachael G. Hunter, Robert R. Lane and Eva R. Hillmann. 2016. "Decline of the Maurepas Swamp, Pontchartrain Basin, Louisiana, and Approaches to Restoration." Water 8 (101): 1-18.

Shaffer, Gary P., William B. Wood, Susanne S. Hoeppner, Thais E. Perkins, Jason Zoller, and Demetra Kandalepas. 2009. "Degradation of Baldcypress-water tupelo Swamp to Marsh and Open Water in Southeastern Louisiana, USA: An Irreversible Trajectory?" Journal of Coastal Restoration 54: 152-165. 
Sims, Daniel A. and John A. Gamon. 2002. "Relationships Between Leaf Pigment Content and Spectral Reflectance Across a Wide Range of Species, Leaf Structures and Developmental Stages." Remote Sensing of Environment 81: 337-354.

Strahler, Alan H., Wolfgang Lucht, Crystal Barker Schaaf, Trevor Tsang, Feng Gao, Xiaowen Li, Jan-Peter Muller, Philip Lewis, Michael J. Barnsley. 1999. MODIS BRDF/Albedo Product: Algorithm Theoretical Basis Document Version 5.0. MODIS Product Document ID: MOD43. https://modis.gsfc.nasa.gov/data/atbd/atbd_mod09.pdf.

Suir, Glenn M., and Charles E. Sasser. 2017. Floristic Quality Index of Restored Wetlands in Coastal Louisiana. ERDC/EL TR-17-15. Vicksburg, MS: U.S. Army Engineer Research and Development Center.

Suir, Glenn M., and Charles E. Sasser. 2019a. "Redistribution and Impacts of Nearshore Berm Sediments on the Chandeleur Barrier Islands, Louisiana." Ocean \& Coastal Management 168: 103-116.

Suir, Glenn M., and Charles E. Sasser. 2019b. "Use of NDVI and Landscape Metrics to Assess Effects of Riverine Inputs on Wetland Productivity and Stability." Wetlands 39: 815-830.

Suir, Glenn M., Christina L. Saltus, and Molly K. Reif. 2018. "Geospatial Assessments of Phragmites australis Die-Off in South Louisiana: Preliminary Findings.” ERDC/EL TR-18-9. Vicksburg, MS: US Army Engineer Research and Development Center.

Tarantino Cristina., Maria Adamo, Guido Pasquariello, Francesco Lovergine, Palma Blonda and Valeria Tomaselli. 2012. 8-Band Image Data Processing of the Worldview-2 Satellite in a Wide Area of Applications. Earth Observation. Edited by Dr. Rustam Rustamov. InTech. https://www .intechopen.com/books/earth-observation /8-band-image-data-processing-of-the-worldview-2-satellite-in-a-wide-area-of-applications.

Yang, Limin, Suming Jin, Patrick Danielson, Collin Homer, Leila Gass, Stacie M. Bender, Adam Case, Catherine Costello, Jon Dewitz, Joyce Fry, Michelle Funk, Brian Granneman, Greg C. Liknes, Matthew Rigge, George Xian. 2018. "A New Generation of the United States National Land Cover Database: Requirements, Research Priorities, Design, and Implementation Strategies." ISPRS Journal of Photogrammetry and Remote Sensing (146): 108-123. https://doi.org/10.1016

/j.isprsjprs.2018.09.006.

NOTE: The contents of this technical note are not to be used for advertising, publication, or promotional purposes. Citation of trade names does not constitute an official endorsement or approval of the use of such products. 